\title{
Study of abrasive resistance of composites for dental restoration by ball-cratering
}

\author{
P. Vale Antunes ${ }^{\mathrm{a}}$, A. Ramalho ${ }^{\mathrm{b}, *}$ \\ a Escola Superior de Tecnologia, Instituto Politécnico de Castelo Branco, Av. do Empresário, 6000 Castelo Branco, Portugal \\ ${ }^{\mathrm{b}}$ ICEMS, Departamento de Engenharia Mecânica, Faculdade de Ciências e Tecnologia da Universidade de Coimbra, \\ Pinhal de Marrocos, 3030 Coimbra, Portugal
}

\begin{abstract}
Two-body abrasion occurs in the mouth whenever there is tooth-to-tooth contact. This is what most dentists call attrition. Abrasive wear may also occur when there is an abrasive slurry interposed between two surfaces, such that the two solid surfaces are not actually in contact, this is called three-body abrasion, with food acting as the abrasive agent, and occurs in the mouth during mastication. Abrasion is the key physiological wear mechanism that is present in dental materials during normal masticatory function. The two main categories of restoration materials are dental amalgam and composite restorative material. Although amalgam has excellent mechanical properties, it also has certain limitations and disadvantages. The main negative factors for amalgam are: aesthetic factor, toxicity of mercury, weak adhesion to healthy dental tissue, duration of restoration, corrosion and feeble resistance to fracture.

One of the main objectives in wear studies is to determine the nature of the dependency between the mechanical properties of materials and their tribological behaviour of the surfaces in contact. The aim of the present work is to study the effect of cure conditions on light curable composites on hardness and the respective abrasion resistance. Six commercially available composite restorative materials used for posterior restorations were selected for the study. In order to obtain comparative results one amalgam has been included in the study. The technique of ball-cratering is used to evaluate the resistance to abrasion.
\end{abstract}

(C) 2003 Elsevier Science B.V. All rights reserved.

Keywords: Abrasion; Composite; Hardness; Cure time; Dental restoration

\section{Introduction}

Restoration materials are a sub-group of what are generally called biomaterials: non-living material designed to interact with biological organisms. This study examines some widely used restorative dental biomaterials and their advantages and disadvantages with respect to wear. As the service environment is the mouth, dental restorative materials, and teeth, are subjected to very specific service conditions [1]:

- temperature: -10 to $50{ }^{\circ} \mathrm{C}$;

- saliva as lubricant:

- complex protein-containing salt solution;

- $\mathrm{pH}$ values ranging from 1 to 9;

- contact load: from 1 to $700 \mathrm{~N}$ :

o mastication load: from 6 to $130 \mathrm{~N}$;

o contact stress of $200 \mathrm{MPa}$;

- loading rate: from 1 cycle/s to 1500 cycles per day;

- sliding distance: $30 \mathrm{~km}$ in 50 years tooth lifetime:

\footnotetext{
* Corresponding author. Tel.: +351-239-790756; fax: +351-239-790701.

E-mail address: amilcar.ramalho@dem.uc.pt (A. Ramalho).
}

○ $0.5-1 \mathrm{~mm}$ per cycle;

○ $0.6 \mathrm{~km}$ per year.

The main categories of wear that contribute to the destruction of dental tissues and restorative materials are [2]:

- physiologic wear (vital life functions);

- pathologic wear (disease and abnormal conditions);

- prophylactic wear (preventive measures);

- finishing procedure wear.

In all of these, the actual wear situation may vary significantly as the substrates, opposing wear surfaces, the lubrication systems involved, and the abrasive particles may differ. Table 1 presents a classification of wear situations in dentistry that result from the combination of the different types of wear and the diverse circumstances [3].

The two main categories of dental restoration materials are amalgam and resin-based composite materials.

The amalgam alloy has been used for more then 150 years in the restoration of molars and premolars [4]. Fundamental research has led to such improvements in the mechanical properties of these alloys over the last few years that they have almost achieved an optimal level. The advantages of 
Table 1

Classification of wear situations in dentistry [2]

\begin{tabular}{|c|c|c|c|c|c|}
\hline Intraoral wear event & Type of wear & Lubricant & Substrate & Opponent & Abrasive \\
\hline \multicolumn{6}{|l|}{ Physiologic causes of wear } \\
\hline Non-contact wear & Three-body & Saliva/food & Tooth/restoration & - & Food \\
\hline Direct contact wear & Two-body & Saliva & Tooth/restoration & Tooth/restoration & - \\
\hline Sliding contact wear & Two-body & Saliva & Tooth/restoration & Tooth/restoration & - \\
\hline \multicolumn{6}{|l|}{ Pathologic causes of wear } \\
\hline Bruxism & Two-body & Saliva & Tooth/restoration & Tooth/restoration & - \\
\hline Xerostomia & Two-body & - & Tooth/restoration & Tooth/restoration & - \\
\hline Erosion & - & Saliva & Tooth/restoration & - & - \\
\hline Unusual habits & Two-body & Saliva & Tooth/restoration & Foreign body & - \\
\hline \multicolumn{6}{|l|}{ Prophylactic causes of wear } \\
\hline Toothbrush and dentifrice & Three-body & Water & Tooth/restoration & Tooth brush & Dentifrice \\
\hline Prophylactic pastes & Three-body & Water & Tooth/restoration & Polishing cup & Pumice \\
\hline Scaling and cleaning & Two-body & Water & Tooth/restoration & Instrument & - \\
\hline \multicolumn{6}{|l|}{ Cutting, finishing, polishing } \\
\hline Cutting burs/diamonds & Two-body & Water & Tooth/restoration & Bur & - \\
\hline Finishing burs & Two-body & Water & Tooth/restoration & Bur & - \\
\hline Polishing pastes & Three-body & Water & Tooth/restoration & Polishing cup & Abrasive slurry \\
\hline
\end{tabular}

amalgam are that it rehabilitates masticatory function relatively quickly, and with relatively low associated costs. It allows broad clinical working conditions and high freedom of manipulation. In fact, amalgam is known as a forgiving material.

However, amalgam has some disadvantages. The main negative aspect is its aesthetics. Since it is a metallic restoration, its colour is very different from that of dental tissue. Mercury, as a constituent of amalgam, represents another important disadvantage. It is highly toxic, which implies very careful handling. Other drawbacks are: corrosion, low fracture toughness and the large amount of sound tooth tissue that has to be removed in order to obtain an acceptable cavity shape for good retention. Besides being unlike the tooth structure, it is a brittle material and has a low tensile strength. Some other handicaps of amalgam are: the possible effects of post-operative sensitivity, due to marginal defects existing between amalgam and tooth structure, or local side effects in the oral mucous membranes, as well as systemic effects due to allergic or other kinds of hypersensitivity reactions [5]. All these factors put together, plus the health hazards of amalgam-its use even forbidden in some European countries-have focused dental research on the development of alternatives. This substitute should be a biologically acceptable material, aesthetically pleasing, and it should have an optimal combination of mechanical, physical and chemical properties [6].

Dental composite materials are now being used instead of amalgam. Dental composites are, by definition, three-dimensional combinations of at least two chemically different materials, with a distinct interface separating these components [7]. The major components of dental composites are, in the first place, a matrix, consisting of an organic resin material with pigments, viscosity controllers, poly- merisation initiators, accelerators and inhibitors. Secondly, a dispersed phase, consisting of an inorganic filler material, which may contain polymer particles; and, thirdly, the interface, a coupling agent, which adheres to both the inorganic filler and the matrix materials [8].

Composite materials have the ability to convert from a plastic mass into a rigid solid, which allows this material to be used for the restoration of dentition. Dental composites have the advantage of being used and cured directly in the restoration cavity. They are specially recommended in restorations where occlusal stress is minimal and appearance is crucial. An important disadvantage of composites is the shrinkage effect due to polymerisation. Its usage is also limited by having a shorter duration than amalgam in posterior restoration [9]. The wear resistance of composite restoration is fundamental for clinical longevity, aesthetics and resistance to dental plaque. The most recent scientific research in these areas points to the need for composites to have better wear resistance [10], which is difficult to achieve because the clinical wear mechanisms are not properly understood.

Recent developments in the dental composite industry has resulted in a confusing variety of resin composites appearing on the market, which makes the selection of the correct material for each specific application very difficult. The aim of the present work is to study the effect of the cure time on light curable composites and its effects on the hardness and the abrasion resistance of resin composites. For this study, six commercial resin composites, suitable for posterior restorations, were selected. One amalgam was included in the study for the purpose of comparison. The technique of ball-cratering was used to evaluate the resistance to abrasion. The abraded surfaces were examined by scanning electron microscopy (SEM). 


\section{Experimental procedures}

\subsection{Materials and specimens}

Six commercial composite resins were selected for the present study. The commercial trade names are omitted, to avoid commercial references. The composites are therefore referenced by the capital letters; A, B, C, D, E and F. Table 2 contains information about the matrix composition and type of reinforcement filler, dimension of particles and volume fraction.

An aluminium mould was used to produce disc-shape specimens of composite and amalgam, $10 \mathrm{~mm}$ in diameter and $2 \mathrm{~mm}$ thick. The mould was placed on a transparency film, resting on a glass, filled manually with a slight excess of resin composite and covered in the same manner as the bottom face. Before curing, the composite samples were compacted manually by applying light finger pressure on the upper glass. A $\operatorname{Kerr}^{\circledR}$ polymerisation unit, the Optilux 501 , was used to perform these tasks. The output wavelength range of the curing light varies from 400 to $510 \mathrm{~nm}$, and minimal light intensity of $850 \mathrm{~mW} / \mathrm{cm}^{2}$, using an $8 \mathrm{~mm}$ curved turbo light guide, information taken from the technical description of the manufacturer. Curing times ranged from 10 to $80 \mathrm{~s}$. The tip of the light guide was placed in contact with the upper glass in order to ensure curing efficiency.

The polymerisation unit ensures a curing depth greater than the thickness of the specimens. The curing time range studied differed from specimen to specimen, because some did not exhibit much variation in the hardness values for different curing times. For comparative purposes, a few samples of amalgam with identical geometry were prepared with $\operatorname{Kerr}^{\circledR}$ Automix equipment. The amalgam is composed of spherical particles and its constituents are: $\mathrm{Ag} \mathrm{59 \% ,} \mathrm{Hg}$ $42.5 \%, \mathrm{Cu} 13 \%$ and $\mathrm{Sn} 28 \%$.

\subsection{Hardness}

To determine the influence of curing time on the material hardness of these restoration materials, a Vickers micro-indentation test was performed. Struers Duramin testing equipment was used to apply a load of $1.962 \mathrm{~N}$ for a period of $40 \mathrm{~s}$. Hardness was measured on the face directly exposed to the curing light. Ten indentations were made in the cured surface of each specimen. The Vickers' hardness value of amalgam was used for comparison.

\subsection{Ball-cratering tests}

A micro-abrasion test was performed to determine the abrasion resistance of the chosen materials [11]. This technique is called ball-cratering, and consists of a sphere in rotation rotated with precise motion between points, solidary with a shaft. The sphere is kept in permanent contact with the vertical wear surface of a stationary specimen. A hanging weight is applied to guarantee a normal load. During these tests, abrasive slurry drops continuously by gravity feed, keeping the contact area covered with the slurry. The angular velocity of the shaft can be changed constantly by means of a frequency inverter that feeds the electric motor. The ball-cratering technique is represented schematically in Fig. 1. AISI 52100 steel spheres with $5 \mathrm{~mm}$ radius were used in the tests. This radius is similar to the curvature radius of molars. In order to ensure a good reproductivity, the

Table 2

Composition of resin composite matrixes used in this work: type, dimension and volume fraction of the reinforcement filler particles

\begin{tabular}{|c|c|c|c|c|}
\hline \multirow[t]{2}{*}{ Composite designation } & \multirow[t]{2}{*}{ Matrix } & \multicolumn{3}{|l|}{ Reinforcement filler } \\
\hline & & Type & Dimension $(\mu \mathrm{m})$ & Fraction $(\%)$ \\
\hline A & $\begin{array}{l}\text { TEGDMA } \\
\text { Bis-EMA } \\
\text { UDMA }\end{array}$ & Zirconia/silica & 0.6 & 61 vol. \\
\hline B & Bis-GMA & Barium glass & 0.6 & 79 wt. \\
\hline $\mathrm{C}$ & $\begin{array}{l}\text { TEGDMA } \\
\mathrm{a} \\
\mathrm{b}\end{array}$ & $\begin{array}{l}\text { Barium glass } \\
\text { Strontium glass }\end{array}$ & 2 & $80 \mathrm{wt}$. \\
\hline $\mathrm{D}$ & $\begin{array}{l}\text { TEGDMA } \\
\mathrm{b}\end{array}$ & Barium glass & 0.7 & 78 wt. \\
\hline E & Urethane modified Bis-GMA & Barium/silica glass & Mixture of different size particles & $81.5 \mathrm{wt}$. \\
\hline $\mathrm{F}$ & $\begin{array}{l}\text { TEGDMA } \\
\text { Bis-GMA } \\
\text { Bis-EMA }\end{array}$ & Strontium/barium silica & 0.6 & 74 wt. \\
\hline
\end{tabular}

Bis-EMA: bisphenol diglycidylmethacrylate; UDMA: urethane dimethacrylate; Bis-GMA: bisphenol A polyethylene glycol diether dimenthacrylate; TEGDMA: tri[ethylene glycol] dimethacrylate.

${ }^{a}$ Bisphenol A diglycidylurethacrylate.

${ }^{\mathrm{b}}$ Ethoxylate Bisphenol A dimethacrylate. 


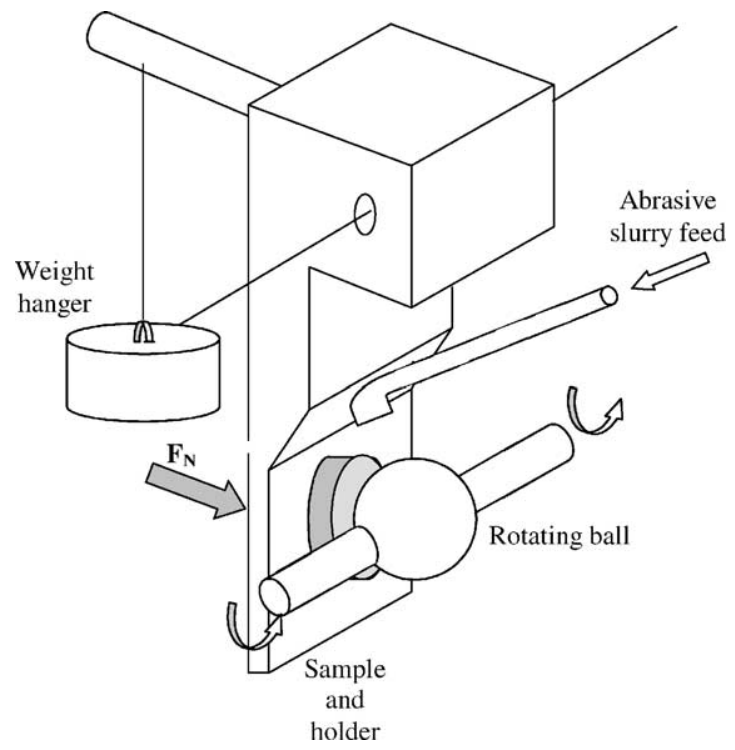

Fig. 1. Diagram representing the ball-cratering technique.

steel spheres where chemically etched [12]. This provides an adequate roughness to sphere surface. A new ball was used for each specimen. The normal load $F_{\mathrm{N}}$ applied to the contact was $0.5 \mathrm{~N}$ and the rotation velocity of the sphere was $100 \mathrm{rpm}$, corresponding to a linear nominal velocity of $0.052 \mathrm{~m} / \mathrm{s}$. The duration of the tests was $50,100,200$ and 300 rotations. Two tests for each of the four numbers of rotations were carried out on each specimen, so that each specimen was subjected to eight tests. The abrasive slurry used in the tests was an aqueous suspension of $0.35 \mathrm{~g}$ of glass micro-spheres per $\mathrm{ml}$ of distilled water. The diameter of the spheres varied from 0.3 to $12 \mu \mathrm{m}$, with a mean value of $4 \mu \mathrm{m}$. The micro-spheres are hollow silica-alumina ceramic spheres with thick walls and they have a hardness of 7 mohs.

A Philips XL30 TMP scanning electron microscope was used to measure the wear scars and examine the morphology of the crater in the wear surface. The wear scars were spherical in shape and their diameter was measured in two orthogonal directions, i.e. the direction of motion and the direction perpendicular to it. The average values of crater radius, $r$, as well as the sphere radius, $R$, were then used to calculate the depth, $h$, and volume, $V$, of removed material, using the Eqs. (1) and (2).

$$
\begin{aligned}
& h=R-\sqrt{R^{2}-r^{2}} \\
& V=\frac{\pi}{3} h^{2}(3 R-h)
\end{aligned}
$$

\section{Results and discussion}

Fig. 2 gives a graphic representation of the micro-hardness, $\mathrm{HV}_{0.2}$, values for each material and corresponding cure time. Representing the hardness values as a function of curing time, it can be seen that most of the materials studied are not greatly affected by the cure time; Fig. 3 shows the evolution of the hardness with the cure time for all the resin composites. The behaviour of the Composites C and D is very similar (Fig. 3); the hardness is almost constant for cure times superior to $40 \mathrm{~s}$. The difference occurs because the hardness of Composite D is greater than the hardness of Composite C.

For every curing time tested, Composite A has the highest hardness values of the resin composites analysed. Its behaviour is unique because there is a great increase in hardness when the cure time increases from 40 to $80 \mathrm{~s}$. Thus, Composite $\mathrm{A}$ is the resin composite that is most sensitive to the curing time.

Composite $\mathrm{E}$ has a similar behaviour to Composite A, although the increase for high cure times, 60 and $80 \mathrm{~s}$, is not so accentuated. This composite also shows good resistance to indentation. Composite $\mathrm{F}$ is not much affected by the cure time although it has the lowest hardness values. Composite $\mathrm{B}$ also has low hardness, and its behaviour is identical to Composite F. Curiously, the hardness value at $40 \mathrm{~s}$ is lower than that obtained for a $20 \mathrm{~s}$ cure time, and this pattern is repeated for the 60 and $80 \mathrm{~s}$ cure time. This composite does not show any special tendency to harden with increasing cure time, and there is little variation in its hardness values.

To summarize, the effect of cure time on the hardness values of the composite materials is not very important, except for Composite A, but, to avoid serious problems in posterior applications, clearly the minimum cure time should be at least $40-60 \mathrm{~s}$. It is also clear that the average hardness value of the amalgam, $185 \mathrm{HV}_{0.2}$ (standard deviation, 11.4), is very high when compared with the values obtained by the hardest composite.

\subsection{Effect of cure time in abrasion resistance}

Ball-cratering is an excellent procedure for determining the abrasion resistance of materials, since it is a very reliable and expeditious technique. This test produces craters which vary proportionally with the number of rotations, maintaining a constant spherical geometry. In order to evaluate the abrasion resistance and the influence of the cure time on the materials under study, graphs of wear rate as a function of curing time were plotted. The wear rate values correspond to the slope of the linearized evolution of the wear volume versus the number of rotations, i.e. the distance covered, in millimetres. For each material, test condition, number of rotations and cure time, a certain wear volume, expressed in $\mathrm{mm}^{3}$, was obtained and the mean value of wear volume for every distance covered determined. For each material and curing time, graphs were plotted showing the corresponding mean wear volume for each of the four distances covered. After this, a numerical regression was carried out so as to allow the calculation of the wear rate, confirming that there 


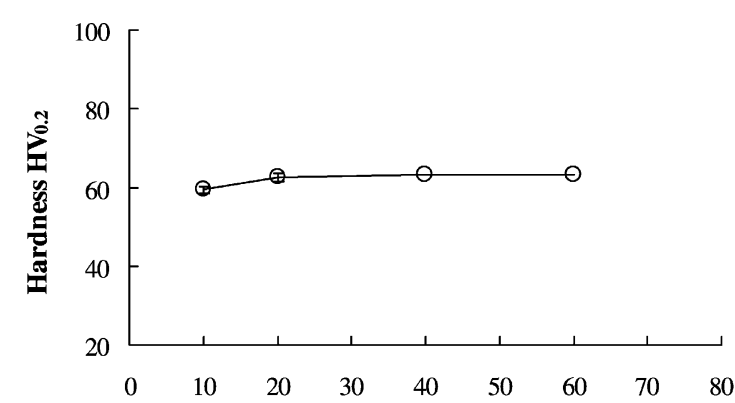

(a)
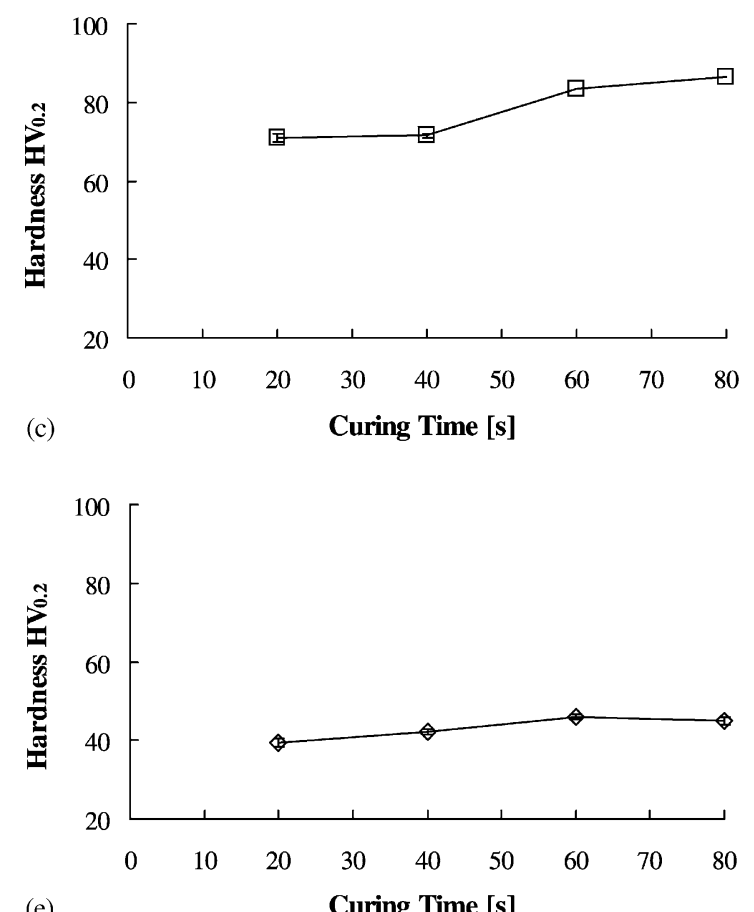

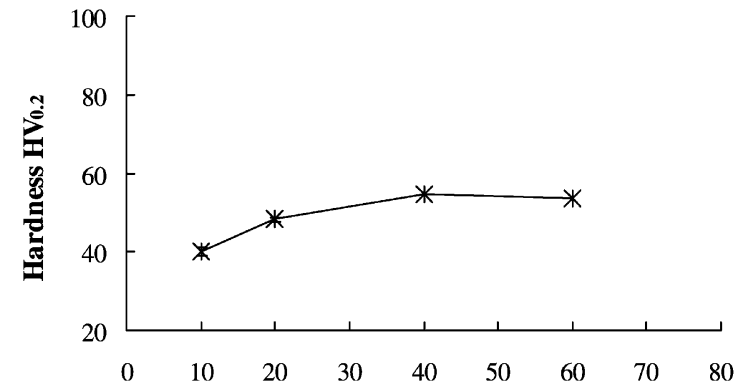

(b)
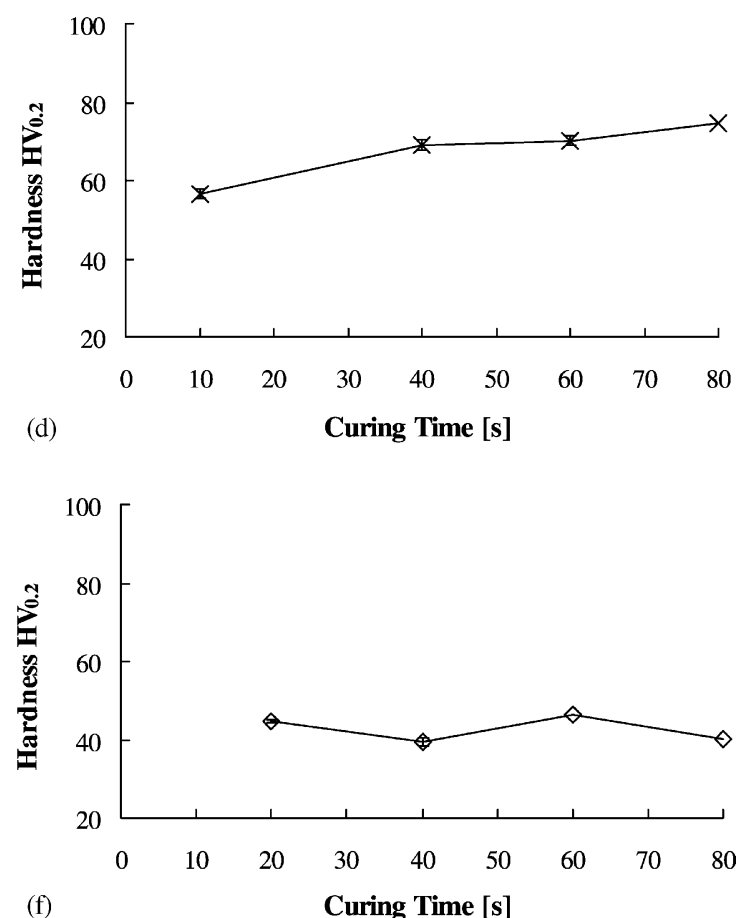

Fig. 2. Evolution of hardness as a function of curing time, for each material tested: (a) Composite D; (b) Composite C; (c) Composite A; (d) Composite E; (e) Composite F; (f) Composite B.

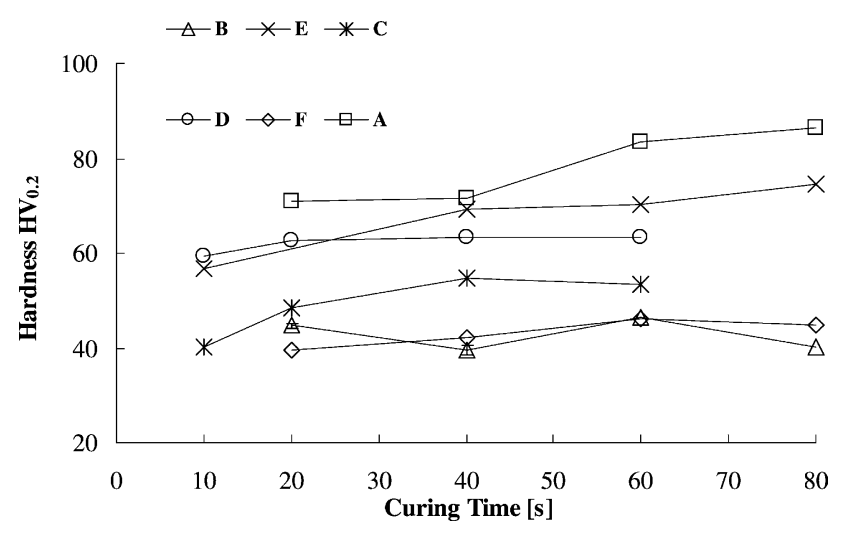

Fig. 3. Evolution of hardness as a function of curing time for all the materials tested. is a linear dependency between the wear volume and the distance covered.

Fig. 4 shows the performance of each composite material relative to abrasion resistance. In Fig. 5, all the materials tested are represented; amalgam has the better results for abrasion resistance, corresponding to the horizontal line in the graph.

Bearing in mind that curing time affects hardness evolution, it was expected that the materials would exhibit an increasing abrasive resistance for higher values of curing time. The experimental results show that this does not always happen. It was possible to identify three quite distinct behaviours.

Composites $\mathrm{E}$ and $\mathrm{A}$, presented a type I behaviour, which is characterized by an increase in the abrasion resistance for higher curing times. These two materials exhibited very similar behaviour, for curing times; up to $60 \mathrm{~s}$, the abrasion resistance increases with the curing time. 

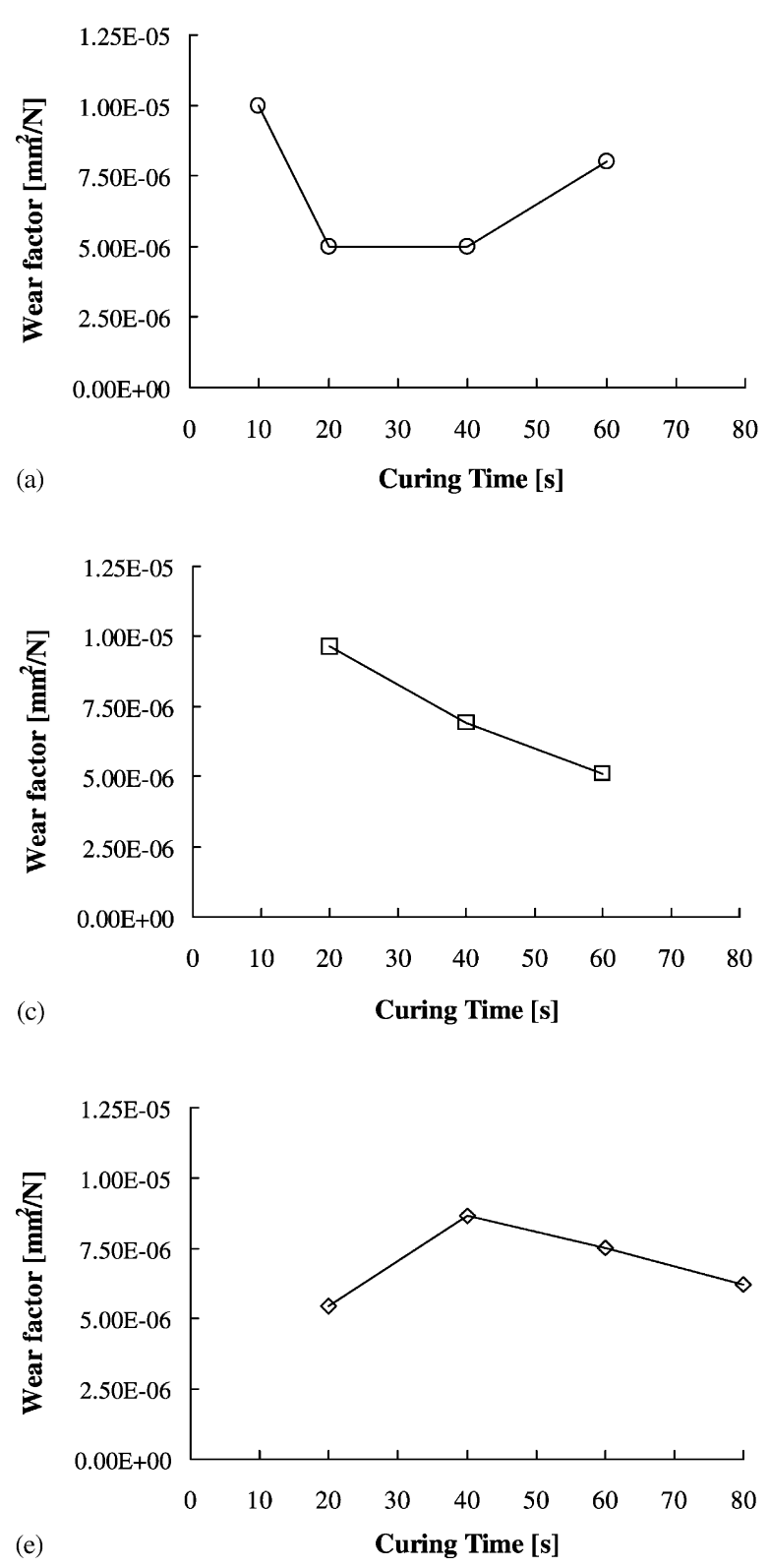
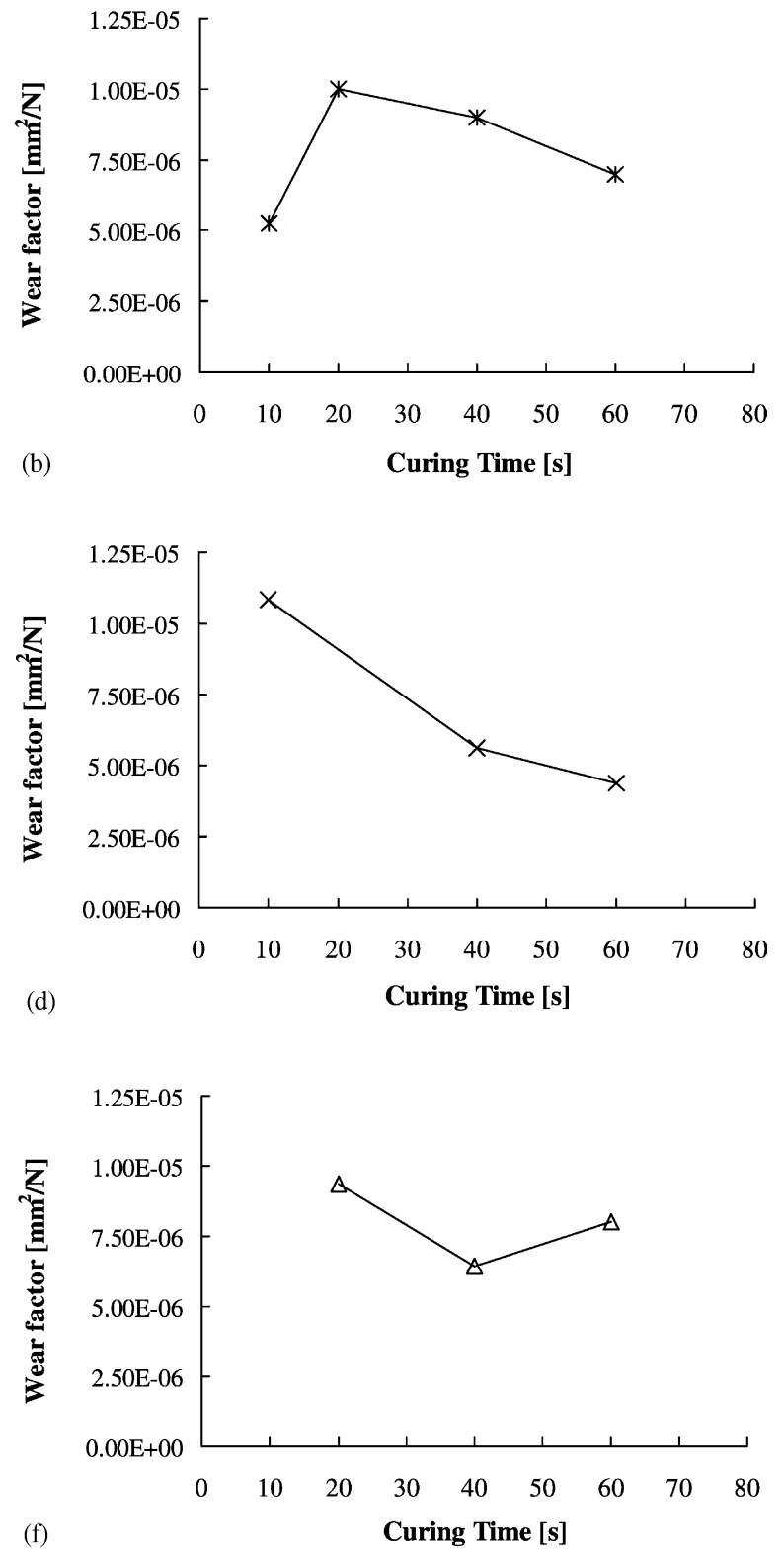

Fig. 4. Evolution of the wear factor as a function of curing time, for each material tested: (a) Composite D; (b) Composite C; (c) Composite A; (d) Composite E; (e) Composite F; (f) Composite B.

Type II behaviour is presented by Composites $\mathrm{F}$ and $\mathrm{C}$. This behaviour is characterized by the existence of curing times that lead to maximum values of abrasion wear. In fact, both materials show a surprisingly high resistance to abrasive wear for short curing times, but then abrasion increases with increased curing time, to a maximum value, and subsequently there is a reduction in abrasion with curing time. However, the minimum abrasion occurred for the lowest curing time.

The type III behaviour is characteristic of Composites B and $\mathrm{D}$. These materials presented optimal curing times that maximize abrasion resistance. In effect, both materials have an intermediate curing time, which leads to a minimum value of the wear factor.
All tested materials showed great sensitivity of wear resistance to the variation in curing time, Fig. 5. In all the studied materials, and for the range of curing times analysed, an overall variation in the wear factor of about five times was observed.

The results of the tests conducted show that the best results in wear factor, for all the composite materials, was $20 \%$ higher than the one obtained for the amalgam.

The results obtained show that hardness cannot be used as the property motivating the selection of the most abrasive-resistant material. However, in general terms, the hardness variation resulting from the change in curing time seems to be directly associated to a variation in the abrasion wear factor in that this factor decreases with increasing 


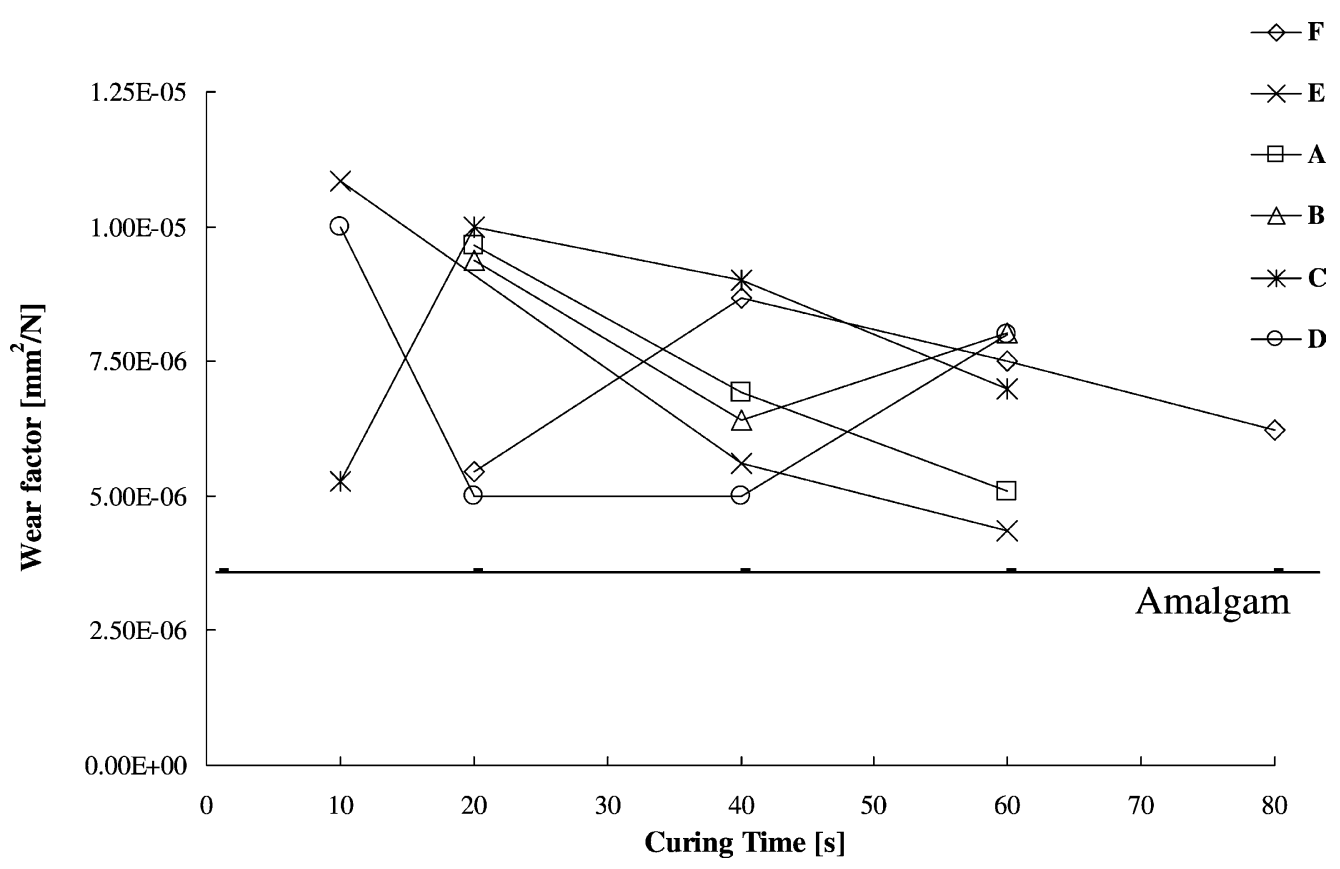

Fig. 5. Plot of the abrasion tests, representing the wear factor for the curing time range for all the tested materials, including amalgam, to which the horizontal line in the graph corresponds.

hardness, as is usual in abrasion phenomena controlled by plastic deformation [13].

\subsection{Morphology}

Regarding the morphology of the tested samples, all were observed under SEM to measure the diameter of the craters and to evaluate what type of abrasion occurred. These observations enabled it to be concluded that, two-body abrasion, took place for all the materials, which is a typical mechanism that happens in the mouth whenever there is a tooth-to-tooth contact, in a process that dentists commonly call attrition. Figs. 6 and 7 show the wear scars, which have a very regular shape. Deep scars due to two-body abrasion can be detected in the composite surface. The dispersion of the reinforcement particles for the resin composite can be seen in Fig. 8. Two-body abrasion also occurs for the other specimens tested, as valleys and peaks caused by the debris are

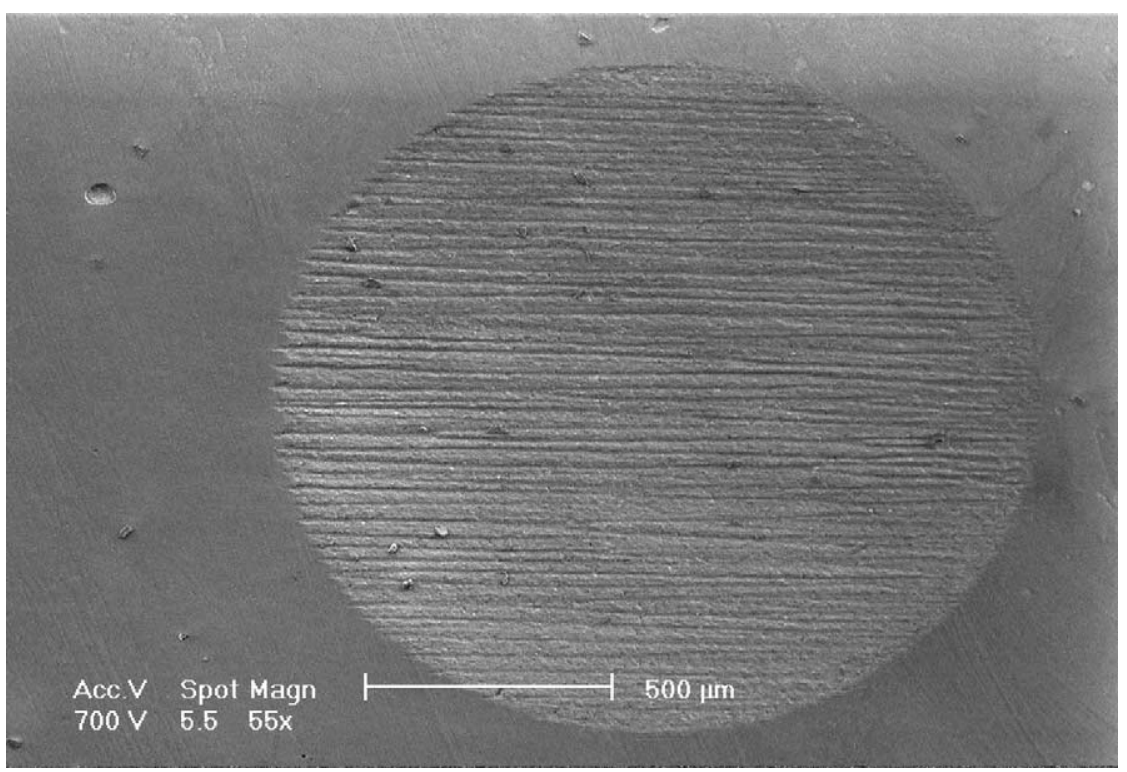

Fig. 6. Typical abrasion scar. Composite $\mathrm{C}$, at $40 \mathrm{~s}$ curing time under abrasion test of 300 rotations. 


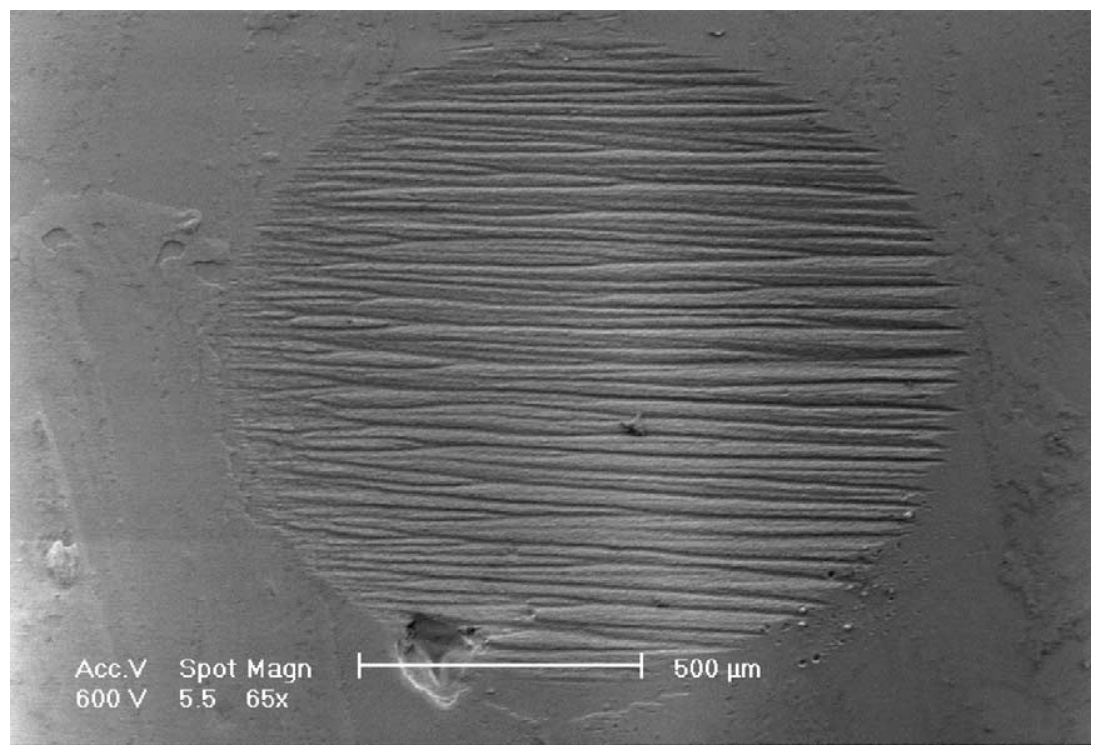

Fig. 7. Typical abrasion scar. Composite B, at 60 s curing time under abrasion test of 100 rotations.

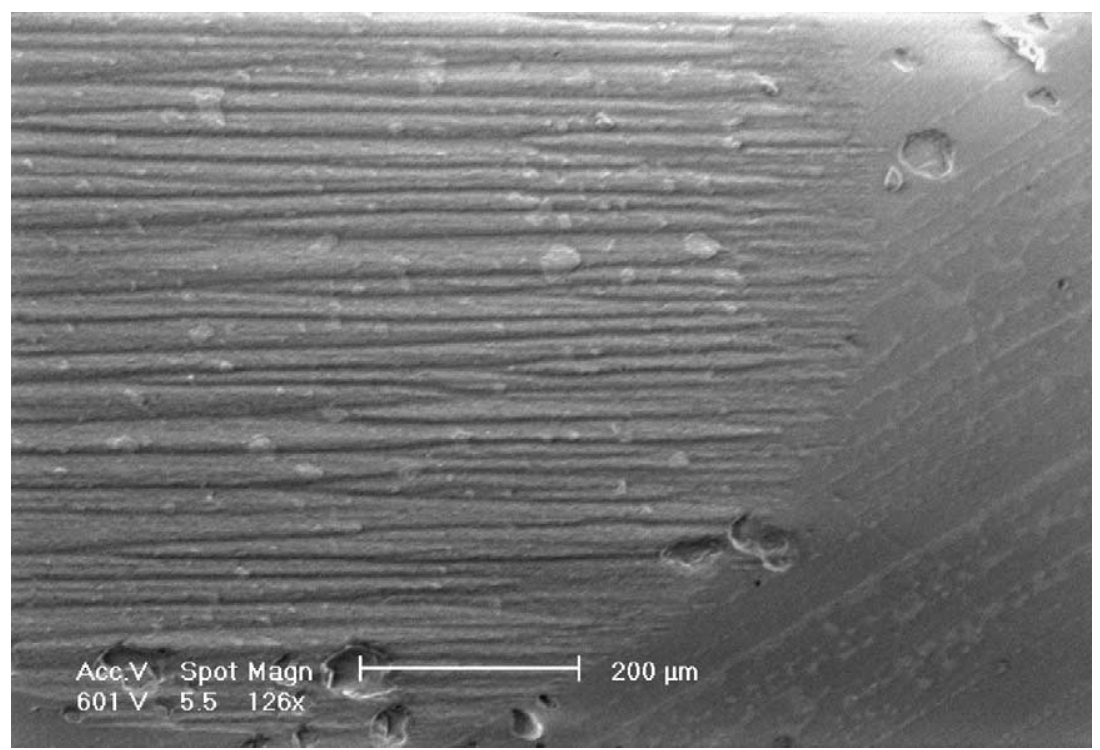

Fig. 8. Detail of an abraded surface with reinforcement particles visible. Resin composite E, at $60 \mathrm{~s}$ curing time under abrasion test of 100 rotations.

clearly visible, abrading both the polymeric matrix and the reinforcement particles. No detaching of reinforcement particles was observed, meaning that the particles were abraded together with the matrix material. Some superficial defects can be also observed in Fig. 8, but these defects did not interfere with the tested area.

\section{Conclusions}

With respect to the effect of curing time on the micro-hardness, it can be concluded that:
- Curing time does not have a major influence on most of the resin composites.

- It is clear that the micro-hardness increases, up to a certain limit.

This study also focused on the relation between curing time and abrasion resistance. Although the findings are only preliminary, the following conclusions can nevertheless be drawn:

- The ball-cratering technique is suitable for the study of dental materials.

- The results yielded by some of the composite materials studied are close to the results presented by the amalgam, 
but are not close enough to reach the abrasion resistance of amalgam.

- The absolute hardness value is not a safe criterion for correctly choosing the material, composite or amalgam, for a dentistry application where abrasive resistance is the more important factor. Although, for each of the materials tested, an increase in the hardness value usually led to improved abrasion resistance.

\section{References}

[1] S. Jahnmir, Wear behavior of dental Ceramics, in: Proceedings of the 7th Portuguese Conference on Tribology, Porto, June 2000.

[2] J.M. Powers, S.C. Bayne, Friction and Wear of Dental Materials, ASM Handbook, vol. 18, ASM International, 1992, pp. 665-681.

[3] I. Mandel, Living with amalgam: an environment perspective, Quint. Int. 22 (1991) 337-339.

[4] M. Bergman, Side effects of amalgam and its alternatives: local, Int. Dent. J. 40 (1990) 4-10.
[5] H.J. Wilson, Resin-based restoratives, Br. Dent. J. 164 (1988) $27-$ 44.

[6] R.W. Phillips, Restorative resins, in: Skinner's Science of Dental Materials, eighth ed., Saunders, Philadelphia, 1982, pp. $217-$ 247.

[7] G. Willems, Multi Standard Criteria for the Selection of Potential Posterior Composites, 1992, Ph.D. Thesis, Kuleuven.

[8] American Dental Association, Council on Dental Materials, Instruments, and Equipment, Posterior Composite Resins, J. Am. Dent. Assoc. 112 (1986) 707-709.

[9] D.F. Taylor (Ed.), Posterior Composites, 1984.

[10] R.A. Draughn, R.L. Bowen, J.P. Moffa, in: J.A. Reese, T.M. Valega (Eds.), Composites Restorative Materials, Restorative Dental Materials, vol. 1, Biddles Ltd., 1985, pp. 75-107.

[11] A. Kassman, S. Jacobson, P. Hedenqvist, M. Olsson, A new test method for the intrinsic abrasion resistance of thin coatings, Surf Coat. Technol. 50 (1991) 75-84.

[12] D.N. Allsop, R.I. Trezona, I.M. Hutchings, The effect of ball surface condition in the micro-scale abrasive wear test, Tribol. Lett. 5 (1998) 259-264.

[13] I. Hutchings, Tribology, Friction and Wear of Engineering Materials, Butterworth/Heinemann, London, 1992. 